Article

\title{
Rational Design of Alginate Lyase from Microbulbifer sp. Q7 to Improve Thermal Stability
}

\author{
Min Yang, Su-Xiao Yang, Zhe-Min Liu@, Nan-Nan Li, Li Li and Hai-Jin Mou * \\ College of Food Science and Engineering, Ocean University of China, Qingdao 266003, China; \\ minyang89@163.com (M.Y.); yangsuxiao66@163.com (S.-X.Y.); ocean2013@126.com (Z.-M.L.); \\ lxgcznlnn@163.com (N.-N.L.); 1lcs0229@163.com (L.L.) \\ * Correspondence: mousun@ouc.edu.cn; Tel./Fax: +86-532-8203-2290
}

Received: 3 June 2019; Accepted: 21 June 2019; Published: 25 June 2019

check for updates

\begin{abstract}
Alginate lyase degrades alginate by the $\beta$-elimination mechanism to produce oligosaccharides with special bioactivities. The low thermal stability of alginate lyase limits its industrial application. In this study, introducing the disulfide bonds while using the rational design methodology enhanced the thermal stability of alginate lyase cAlyM from Microbulbifer sp. Q7. Enzyme catalytic sites, secondary structure, spatial configuration, and molecular dynamic simulation were comprehensively analyzed. When compared with cAlyM, the mutants D102C-A300C and G103C-T113C showed an increase by 2.25 and $1.16 \mathrm{~h}$, respectively, in half-life time at $45^{\circ} \mathrm{C}$, in addition to increases by $1.7^{\circ} \mathrm{C}$ and $0.4^{\circ} \mathrm{C}$ in the melting temperature, respectively. The enzyme-specific activity and $k_{\text {cat }} / K_{m}$ values of D102C-A300C were 1.8- and 1.5-times higher than those of cAlyM, respectively. The rational design strategy that was used in this study provides a valuable method for improving the thermal stability of the alginate lyase.
\end{abstract}

Keywords: alginate lyase; thermal stability; rational design; disulfide bond; molecular dynamic simulation

\section{Introduction}

Alginate lyases are derived from abundant sources, including bacteria, brown seaweed, and marine mollusks [1]. Alginate lyases are divided into seven polysaccharide lyase (PL) families (PL 5, 6, 7, 14, 15, 17, and 18) in the CAZy database (http://www.cazy.org/Polysaccharide-Lyases.html) based on the identification of amino acid sequences. Alginate lyase degrades alginate by the $\beta$-elimination mechanism to form a double bond between $\mathrm{C} 4$ and $\mathrm{C} 5$ at the non-reducing end [2]. The degradation products, alginate oligosaccharides, and 4-deoxy-L-erythro-5-hexoseulose uronic acid (DEH) are used for various functions in medical and energy industries [3-5]. Previous studies have demonstrated that alginate lyase exhibits poor thermal stability when being incubated with enzymes at above $40{ }^{\circ} \mathrm{C}$ for more than $0.5 \mathrm{~h}$ (residual enzyme activity < 50\%) [6-8]. It is important for alginate lyase to maintain enzyme activity during the process of degrading alginate.

Protein engineering, including directed evolution and rational design, is an effective technology for improving enzyme properties [9]. Directed evolution is the construction of a mutant library by random mutagenesis, and the mutants are then screened according to the target performance. The enzyme activity of $\beta$-(1,4)-mannanases [10] and catalytic activity and thermal stability of tyrosine phenol-lyase [11] have been improved by directed evolution. The success of this method is highly dependent on the size and quality of the mutant library [12]. In contrast, rational design is an effective method for improving the enzyme properties by computer simulation-predicted mutation sites. The catalytic activity of XynB [12] and alginate lyase AlgL [13] and the thermal stability of alkaline pectate lyase [14], phytase [15], and alginate lyase NitAly [16] have been enhanced by rational design. 
The disulfide bonds can increase protein stability by reducing the entropy of the protein unfolding process [17]. The introduction of disulfide bonds in a protein is a type of rational design that can effectively improve protein thermal stability [18]. The current strategy of introducing disulfide bonds in proteins, e.g., lipase B from Candida antarctica [19], PhyA from Acidobacteria [20], and alkaline $\alpha$-amylase from Alkalimonas amylolytica [21], uses computational tools to predict the disulfide bonds, and then screens the mutants by molecular dynamic (MD) simulation. However, the computational tools often predict a high number of potential disulfide bonds, while failing to effectively identify the valid candidates and inactivated enzymes. Therefore, further information is required to precisely select the potential disulfide bonds to improve the enzyme thermal stability.

The alginate lyase cAlyM belonging to PL7 from Microbulbifer sp. Q7 has been expressed in Escherichia coli, and its particular properties have also been depicted [22]. However, cAlyM cannot meet the demand for industrial preparation of alginate oligosaccharides, owing to its low thermal stability. In this study, analyzing the catalytic motif, secondary structure characteristics, spatial configuration, and MD simulation screened the disulfide bonds. The mutants with disulfide bonds were obtained by site-directed mutagenesis. The properties and structure-function relationship of mutants with disulfide bonds were investigated, and the mutant D102C-A300C exhibiting significantly improved thermal stability was obtained.

\section{Results}

\subsection{Selection of Potential Disulfide Bonds in cAlyM}

The amino acid sequences of cAlyM and the other characterized PL7 family alginate lyases were aligned to determine the conservative residues. 19 residues were fully conserved, viz., Trp55, Pro60, Thr106, Tyr112, Arg114, Glu116, Leu117, Arg118, Gln183, Ile184, His185, Leu240, Tyr286, Phe287, Lys288, Ala289, Gly290, Tyr292, and Gln294, as shown in Figure 1A. Of these, Gln183, Ile184, and His185 corresponded to the catalytic residues proposed to exist in PL-7 alginate lyases [23,24]. The crystal structure of alginate lyase from Klebsiella pneumoniae (PDB code: 4OZX, 100.0\% confidence, 98\% coverage, $61 \%$ identity) was used as the template. Reliability analysis by the Ramachandran plot and Profile-three-dimensional (3D) showed that the model was reliable (Figure S1).

A total of 26 potential disulfide bonds were predicted by the DS software (Table S1). Based on the analysis of the score value, the disulfide bonds G171C-V176C, S47C-L52C, and N214C-G277C, which showed low scores $(<70)$, were removed. The disulfide bond W55C-L117C was removed, as the amino acid inside the catalytic pocket may hamper enzyme activity. The disulfide bonds I128C-G135C, I184C-P191C, and V248C-V257C were removed, because the distances of the two residues in primary structure were less than 10 amino acids, which may negatively affect the native structure [25]. The disulfide bonds E119C-Y286C, and G182C-L194C, which were located at less than 5 A with catalytic amino acids, were removed, to ensure the integrity of the catalytic motif [26]. The flexibility of the enzyme was estimated by the root-mean-square deviation (RMSD) values. In comparison, the remaining 17 mutants with overall flexibility were selected as high rigidity mutants and they showed the potential ability to improve enzyme thermal stability $[27,28]$. Of these, six mutants showed lower RMSD values than those of cAlyM (Table 1). The six mutants were used for further studies, and the positions of the disulfide bonds in the model are shown in Figure 1B. 

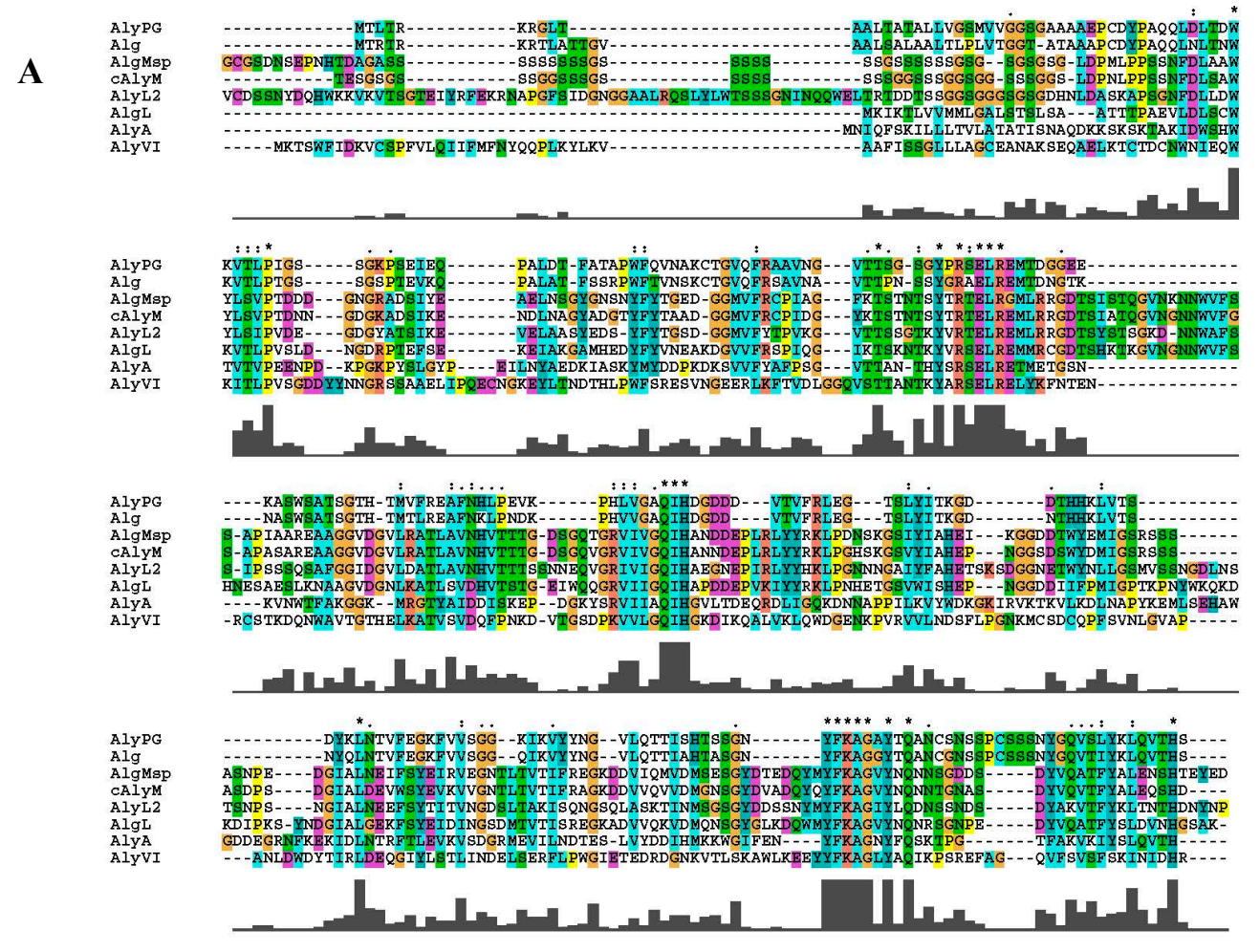

B

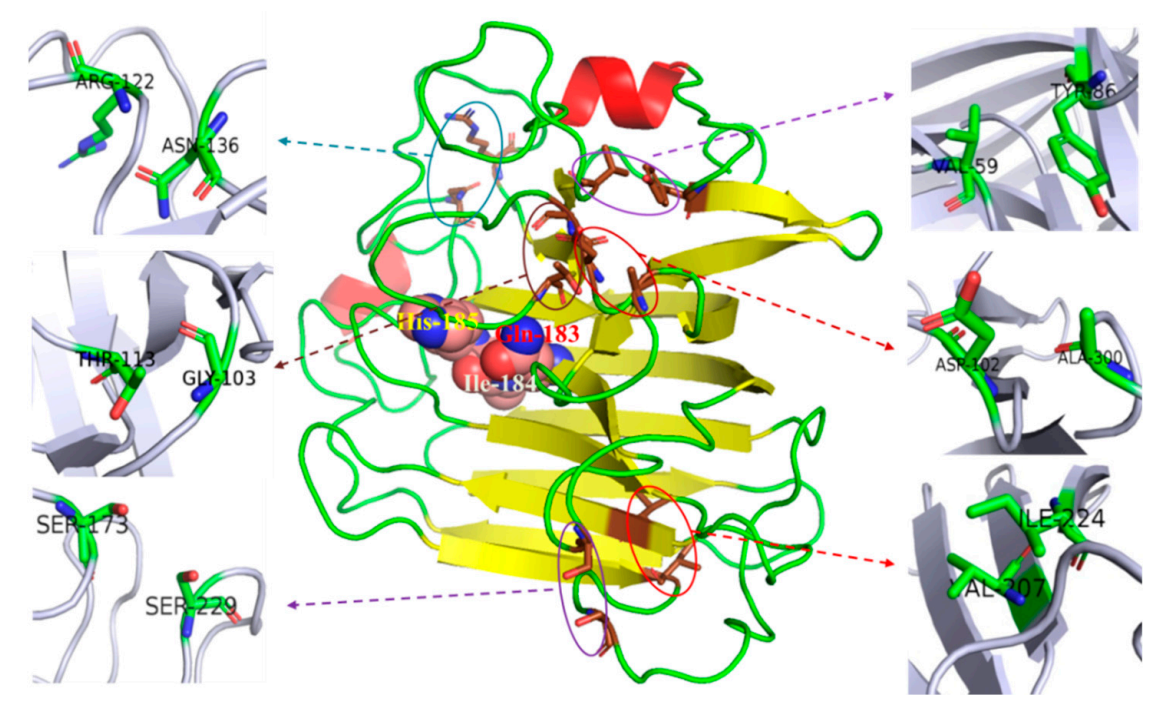

Figure 1. Analysis of the primary and tertiary structure of cAlyM. (A) Comparison among the amino acid sequences of cAlyM and several characterized family PL-7 alginate lyases. AlyPG, Corynebacterium sp. ALY-1 polyguluronate lyase (GenBank accession no: BAA83339.1); Alg, Streptomyces sp. ALG5 alginate lyase precursor (GenBank accession no: ABS59291.1); AlgMap, Microbulbifer sp. 6532A alginate lyase (GenBank accession no: BAJ62034.1); AlyL2, Agarivorans sp. L11 (GenBank accession no: AJO61885.1); AlgL, Agarivorans sp. JAM-A1m alginate lyase (GenBank accession no: BAG70358.1); AlyA, Flavobacterium sp. UMI-01 alginate lyase (GenBank accession no: BAP05660.1); AlyVI Vibrio sp. QY101 alginate lyase (GenBank accession no: AAP45155.1). Residues invariant among all listed proteins are indicated with an asterisk. Catalytic residues proposed in PL-7 alginate lyases are shown as solid circles. (B) The three-dimensional (3D) model of cAlyM and position of the six disulfide bonds (V59C-Y86C, D102C-A300C, G103C-T113C, R122C-N136C, S173C-S229C, and V207C-I224C). Three-dimensional molecular visualization was performed while using the PyMOL 2.1.1 software. In the cAlyM model, the brown amino acids indicate mutation sites, and the arrows point to their magnified structures. The catalytic residues Gln183, Ile184, and His185 are shown according to CPK (Corey-Pauling-Koltun) coloring. 
Table 1. Comparison of the average overall root-mean-square deviation (RMSD) and root mean square fluctuation (RMSF) values of the mutation sites of cAlyM and its mutants.

\begin{tabular}{ccccccc}
\hline \multirow{2}{*}{ Mutants } & \multicolumn{3}{c}{ Average Overall RMSD } & \multicolumn{3}{c}{ Mutation Sites RMSF } \\
\cline { 2 - 6 } & cAlyM & Mutants & $\begin{array}{c}\text { RMSD (cAlyM } \\
\text {-Mutants) }\end{array}$ & cAlyM & Mutants & $\begin{array}{c}\text { RMSF (cAlyM } \\
\text {-Mutants) }\end{array}$ \\
\hline V59C-Y86C & 1.022 & 0.925 & 0.097 & 0.965 & 0.921 & 0.044 \\
D102C-A300C & & 1.004 & 0.018 & 1.277 & 1.204 & 0.073 \\
G103C-T113C & 0.996 & 0.026 & 0.868 & 0.994 & -0.126 \\
R122C-N136C & 1.003 & 0.019 & 0.921 & 0.869 & 0.052 \\
S173C-S229C & 0.989 & 0.033 & 1.772 & 1.201 & 0.571 \\
V207C-I224C & 0.962 & 0.060 & 0.856 & 0.823 & 0.033 \\
\hline
\end{tabular}

\subsection{Determination of Disulfide Bonds of Enzymes}

Mutants with disulfide bonds (V59C-Y86C, D102C-A300C, G103C-T113C, R122C-N136C, S173C-S229C, and V207C-I224C) were successfully constructed and expressed in E. coli BL21. The molecular weights of the purified cAlyM and its mutants were estimated at approximately $33 \mathrm{kDa}$ by sodium dodecyl sulfate-polyacrylamide gel electrophoresis (SDS-PAGE) (Figure 2).

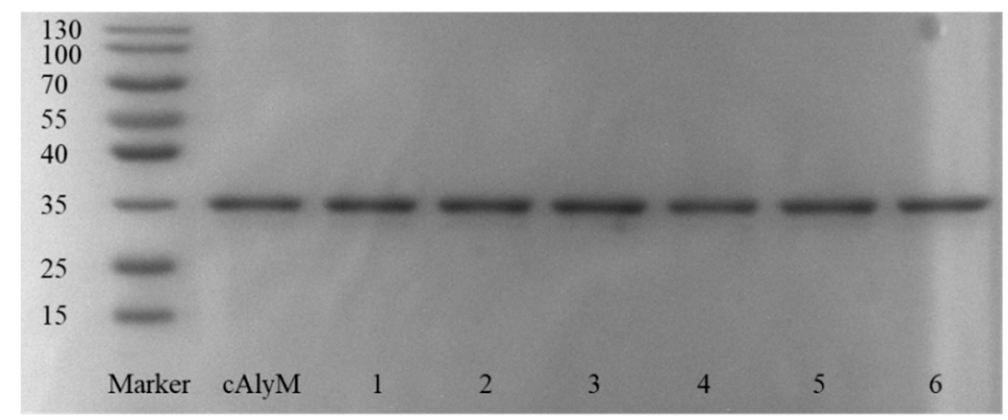

Figure 2. Sodium dodecyl sulfate-polyacrylamide gel electrophoresis (SDS-PAGE) analysis of alginate lyases cAlyM and its mutants. 1, V59C-Y86C; 2, D102C-A300C; 3, G103C-T113C; 4, R122C-N136C; 5, S173C-S229C; 6, V207C-I224C. The enzymes were purified using the Ni-NTA agarose column and detected by SDS-PAGE.

The content of free sulfhydryl groups in cAlyM under reducing conditions $(361.8 \mu \mathrm{mol} / \mathrm{g}) \mathrm{kept}$ a similar level to that of under non-reducing conditions $(351.1 \mu \mathrm{mol} / \mathrm{g})$, which means that there was no disulfide bond formed in cAlyM. The contents of free sulfhydryl groups in the mutants V59C-Y86C, D102C-A300C, G103C-T113C, R122C-N136C, and V207C-I224C under reducing conditions were 439.3, $418.4,421.2,427.3$, and $434.9 \mu \mathrm{mol} / \mathrm{g}$, respectively, which were higher than those of under non-reducing conditions (385.1, 359.3, 371.6, 379.8, and $382.6 \mu \mathrm{mol} / \mathrm{g})$. It indicated that new disulfide bonds formed in these mutants. However, mutant S173C-S229C did not form new disulfide bond, according to the content of free sulfhydryl groups, although it introduced more cysteines when compared with cAlyM.

\subsection{Enzymatic Properties of the Enzymes}

When cmpared with cAlyM, the optimal temperature of D102C-A300C, G103C-T113C, and S173C-S229C remained unchanged at $55^{\circ} \mathrm{C}$ (Figure 3A). The optimal temperatures of V59C-Y86C, R122C-N136C, and V207C-I224C, were $45^{\circ} \mathrm{C}, 40^{\circ} \mathrm{C}$, and $50^{\circ} \mathrm{C}$, respectively, and they were lower than the optimal temperature of cAlyM. As shown in Figure 3B, the optimal pH of R122C-N136C remained unchanged as compared with that of cAlyM at 7.0. The optimal pH of V59C-Y86C, D102C-A300C, G103C-T113C, S173C-S229C, and V207C-I224C was 8.0. The enzyme activity of cAlyM and its mutants was determined at the enzyme optimal temperature and $\mathrm{pH}$ (Figure 3C). When compared with cAlyM, D102C-A300C, S173C-S229C, and V207C-I224C showed higher enzyme activity. Figure 3D shows the 
results of enzyme thermal stability. The half-life values at $45^{\circ} \mathrm{C}\left(\mathrm{t}_{1 / 2}, 45^{\circ} \mathrm{C}\right)$ of cAlyM and the mutants V59C-Y86C, D102C-A300C, G103C-T113C, R122C-N136C, S173C-S229C, and V207C-I224C were 1.90 and $0.37,4.15,3.06,0.75,0.56$, and $0.41 \mathrm{~h}$, respectively.

A

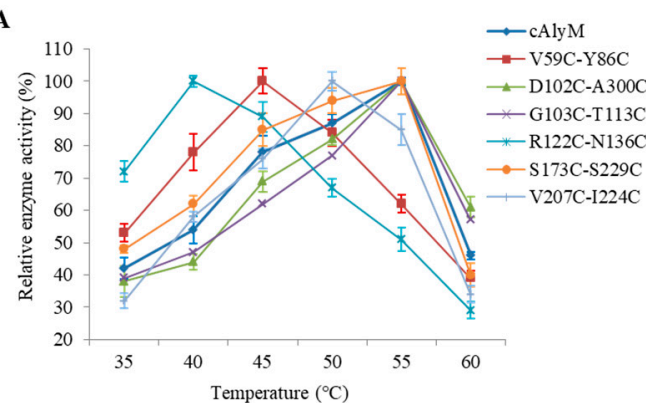

C

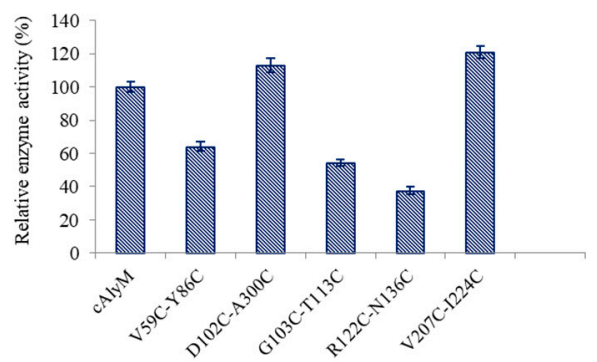

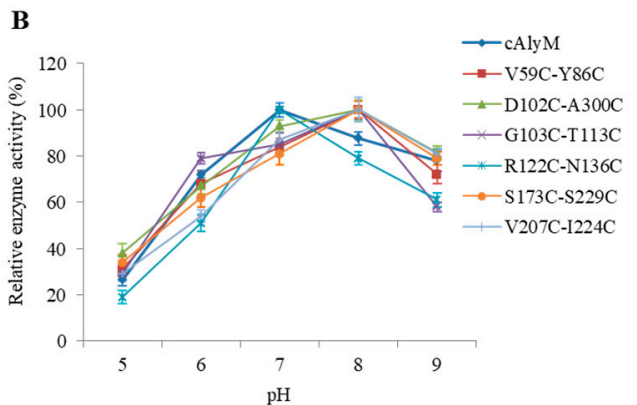

D

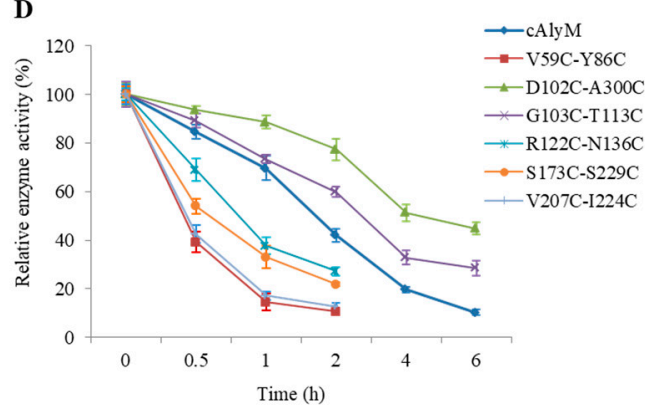

Figure 3. The optimal temperatures (A), $\mathrm{pH}(\mathbf{B})$, enzyme activity at optimal temperature and $\mathrm{pH}(\mathbf{C})$, and thermal stability at $45^{\circ} \mathrm{C}$ (D) of cAlyM and its mutants. The thermal stability of cAlyM and its mutants was investigated by measuring the residual alginate lyase activity of the enzyme after incubation at $45^{\circ} \mathrm{C}$ for $6 \mathrm{~h}$.

As shown in Table 2, the $K_{m}$ and $k_{\text {cat }}$ values of cAlyM were $0.37 \mathrm{mg} / \mathrm{mL}$ and $762.4 \mathrm{~s}^{-1}$, respectively. The $K_{m}$ and $k_{\text {cat }}$ values of the mutant V207C-I224C were the lowest and highest at $0.21 \mathrm{mg} / \mathrm{mL}$ and $921.5 \mathrm{~s}^{-1}$, respectively. $k_{\text {cat }}$ and $K_{m}$ values of D102C-A300C, S173C-S229C, and V207C-I224C were higher than those of cAlyM, indicating a higher catalytic efficiency toward alginate. The Tm values of D102C-A300C and G103C-T113C were $58.9^{\circ} \mathrm{C}$ and $57.4{ }^{\circ} \mathrm{C}$, respectively, which were $1.7^{\circ} \mathrm{C}$ and $0.4{ }^{\circ} \mathrm{C}$ higher than those of cAlyM, whereas the other four mutants showed lower Tm values (Table 2).

Table 2. Kinetic parameters and Tm value of cAlyM and its mutants.

\begin{tabular}{cccccc}
\hline Enzymes & $\boldsymbol{K}_{\boldsymbol{m}}(\mathbf{m g} / \mathbf{m L})$ & $\boldsymbol{V}_{\max }(\mathbf{U} / \mathbf{m g})$ & $\boldsymbol{K}_{\text {cat }}\left(\mathbf{s}^{-\mathbf{1}}\right)$ & $\boldsymbol{K}_{\text {cat }} / \boldsymbol{K}_{\boldsymbol{m}}(\mathbf{m L} / \mathbf{s} / \mathbf{m g})$ & $\mathbf{T m}\left({ }^{\circ} \mathbf{C}\right)$ \\
\hline cAlyM & $0.37 \pm 0.09$ & $1386.3 \pm 23.5$ & $762.4 \pm 19.6$ & 2060.7 & 57.2 \\
V59C-Y86C & $0.95 \pm 0.21$ & $1166.9 \pm 19.2$ & $641.8 \pm 18.5$ & 675.6 & 54.3 \\
D102C-A300C & $0.28 \pm 0.04$ & $1567.6 \pm 52.4$ & $862.2 \pm 30.3$ & 3079.2 & 58.9 \\
G103C-T113C & $1.26 \pm 0.32$ & $754.7 \pm 16.8$ & $415.1 \pm 15.5$ & 329.4 & 57.6 \\
R122C-N136C & $1.94 \pm 0.28$ & $521.6 \pm 17.2$ & $286.9 \pm 14.4$ & 147.9 & 55.6 \\
S173C-S229C & $0.31 \pm 0.08$ & $1455.1 \pm 42.8$ & $800.33 \pm 32.3$ & 2581.7 & 55.4 \\
V207C-I224C & $0.21 \pm 0.07$ & $1675.4 \pm 37.2$ & $921.5 \pm 28.6$ & 4387.9 & 55.4 \\
\hline
\end{tabular}

\subsection{Analysis of the Molecular Structure of cAlyM Mutants}

RMSD and RMSF values, non-covalent bonds, surface charge, and secondary structure of cAlyM and its mutants were determined to understand the molecular mechanism of increased thermal stability induced by the introduction of disulfide bonds.

The RMSD value of the mutants was higher than that of cAlyM. Moreover, the RMSF value of the mutants was also higher than that of cAlyM, except for G103C-T113C (Table 1). It was observed that the overall structure rigidity of the mutants was higher than that of cAlyM, but the local rigidity of 
G103C-T113C was lower than that of cAlyM. Table 3 shows the changes in the H-bonds, salt bond, and hydrophobic interactions between cAlyM and its mutants. The number of $\mathrm{H}$-bonds in cAlyM and its mutants (V59C-Y86C, D102C-A300C, G103C-T113C, R122C-N136C, S173C-S229C, and V207C-I224C) were 281, 282, 281, 280, 275, 281, and 281, respectively. Figure 4 shows the changes in the H-bond network within the $5 \AA$ region around the mutant sites between cAlyM and its mutants. The H-bond of S173C-S229C and V207C-I224C remained unchanged. The H-bond of D102C-A300C between D102 and G103 changed to I101 and C300. One native H-bond between P100 and T113 was lost in G103C-T113C. R122C-N136C lost six H-bonds, two between E74 and R122, one between R122 and I128, one between R122 and T130, one between N136 and N137, and one between T130 and N136. One new H-bond was formed between T85 and C86 in V59C-Y86C. When compared with cAlyM, the number of salt bonds in D102C-A300C and R122C-N136C decreased and those in the other mutants remained unchanged. Moreover, when compared with cAlyM, the number of hydrophobic interactions in G103C-T113C and R122C-N136C increased, whereas those in V59C-Y86C and V207C-I224C decreased. As shown in Figure S2, as compared with cAlyM, the surface charge around the mutant sites of G103C-T113C, R122C-N136C, and V207C-I224C remained unchanged. The surface charge around the mutant sites of V59C-Y86C, D102C-A300C, and S173C-S229C was slightly more positive than that of cAlyM.

Table 3. The number of bonds in cAlyM and its mutants.

\begin{tabular}{cccccccc}
\hline Mutants & cA1yM & V59C-Y86C & D102C-A300C & G103C-T113C & R122C-N136C & S173C-S229C & V207C-I224C \\
\hline H-bond & 281 & 282 & 281 & 280 & 275 & 281 & 281 \\
$\begin{array}{c}\text { Salt-bond } \\
\text { Hydrophobic }\end{array}$ & 26 & 26 & 25 & 26 & 24 & 26 & 26 \\
interaction & 120 & 117 & 120 & 126 & 121 & 120 & 118 \\
\hline
\end{tabular}

A

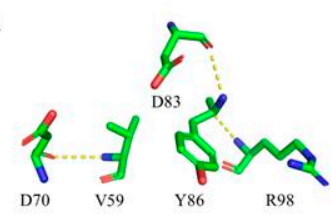

C

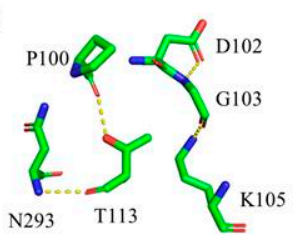

$\mathbf{E}$

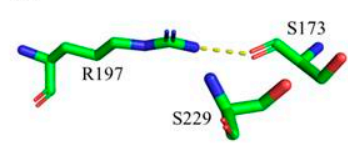

Mutants
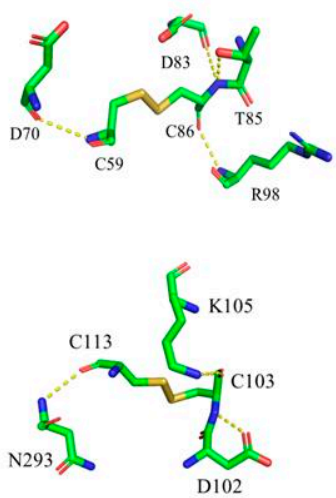

B

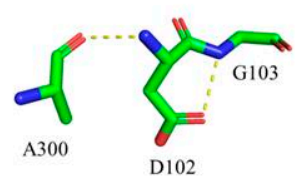

D

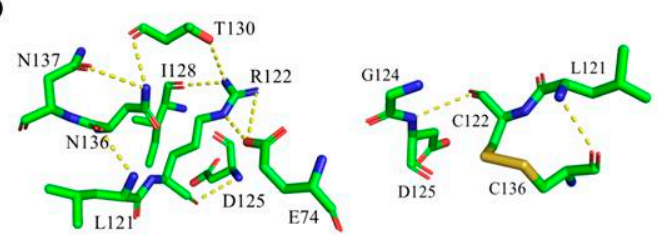

$\mathbf{F}$

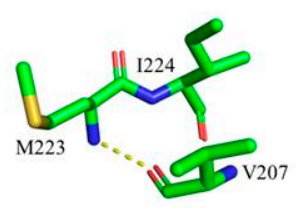

Mutants
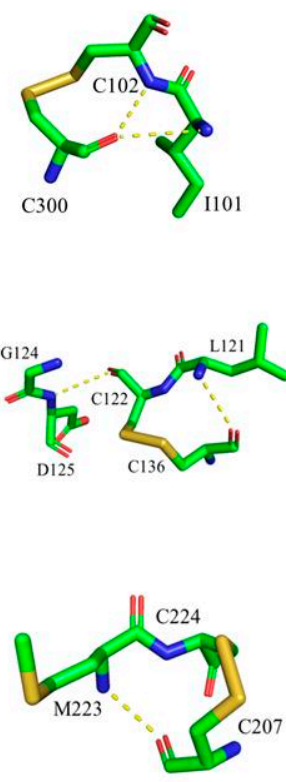

Figure 4. Comparison of the $\mathrm{H}$-bond network within the $5 \AA$ Aregion around the mutant sites between cAlyM and the mutants. (A) V59C-Y86C; (B) D102C-A300C; (C) G103C-T113C; (D) R122C-N136C; (E) S173C-S229C; (F) V207C-I224C.

The secondary structure of cAlyM and D102C-A300C were analyzed while using CD. The CD spectra showed that their secondary structures were almost similar (Figure 5). Both of the enzymes displayed a peak at $195 \mathrm{~nm}$ and a valley at $220 \mathrm{~nm}$. The results indicated that both of the enzymes 
were primarily composed of $\beta$-sheets and $\beta$-turns. The percentages of $\alpha$-helix, $\beta$-sheet, $\beta$-turn, and random coil were $2.53 \%, 35.76 \%, 46.89 \%$, and $14.82 \%$, respectively.

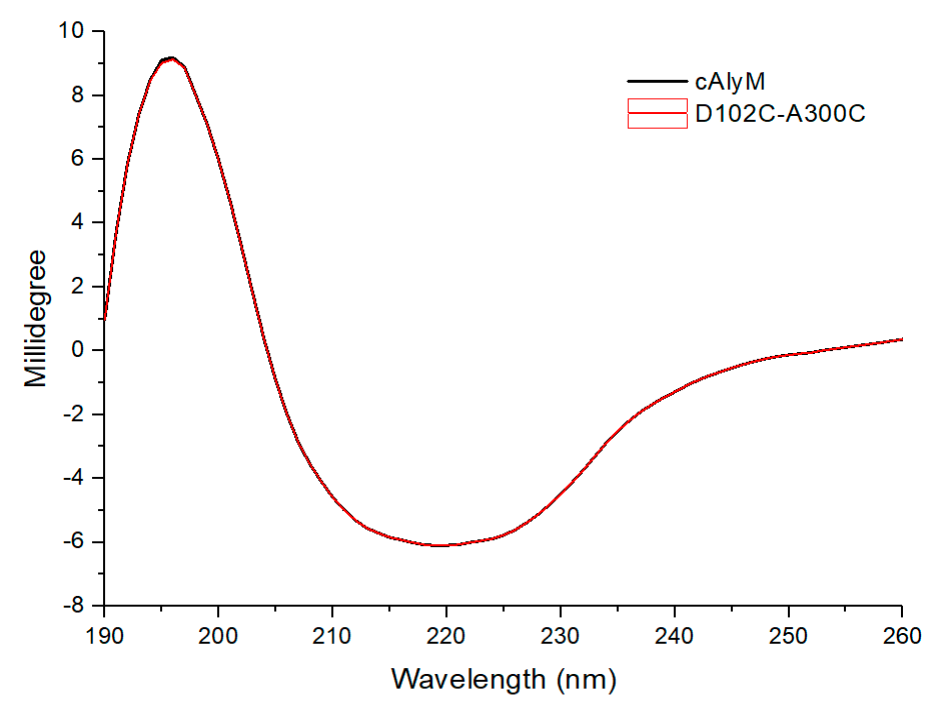

Figure 5. Comparison of the Circular Dichroism (CD) spectra of cAlyM and D102C-A300C. The concentration of enzymes in $20 \mathrm{mM}$ phosphate buffer ( $\mathrm{pH} 7.4$ ) was set at $0.5 \mathrm{mg} / \mathrm{mL}$, and $20 \mathrm{mM}$ phosphate buffer was used as the blank.

\section{Discussion}

Rational designing is a common method of improving the thermal stability of an enzyme. The introduction of disulfide bonds as a type of rational design is an effective strategy for improving protein thermal stability [18]. However, the introduction of inappropriate disulfide bonds may reduce the enzyme activity. An adequate strategy for selecting disulfide bonds is crucial for improving enzyme thermal stability. In this study, the strategy of selected disulfide bonds was based on the analysis of catalytic sites, secondary structure, spatial distance, and 3D-structure flexibility and showed high efficiency. Among the six mutants, there were five mutants that successfully formed new disulfide bonds.

In previous studies, the alginate lyases have exhibited poor thermal stability, such as alginate lyase PA1167 from Pseudomonas aeruginosa (remaining activity $25 \%$ after incubation at $45^{\circ} \mathrm{C}$ for $10 \mathrm{~min}$ ) [6], alginate lyase Algb from Vibrio sp. W13 (remaining activity $30 \%$ after incubation at $40{ }^{\circ} \mathrm{C}$ for $30 \mathrm{~min}$ ) [8], alginate lyase AlyA-OU02 from Vibrio splendidus OU02 (remaining activity $35 \%$ after incubation at

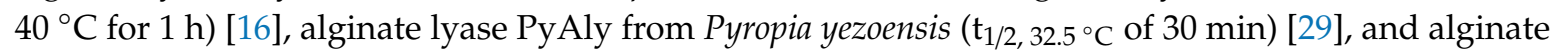

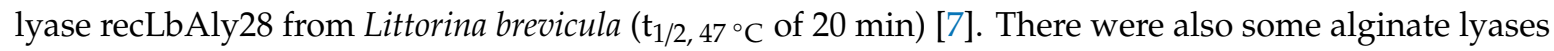
that exhibited good thermal stability, but their enzyme activities were not high. These included alginate lyase AlgC-PL7 from Cobetia sp. NAP1 (remaining activity $90 \%$ after incubation at $50{ }^{\circ} \mathrm{C}$ for $60 \mathrm{~min}$; optimal enzyme activity $24 \mathrm{U} / \mathrm{mg}$ ) [30], alginate lyase rSAGL from Flavobacterium sp. H63 (remaining activity $98.8 \%$ after incubation at $50{ }^{\circ} \mathrm{C}$ for $120 \mathrm{~min}$; optimal enzyme activity $4.04 \mathrm{U} / \mathrm{mg}$ ) [31], and alginate lyase Aly7B_Wf from marine bacterium (remaining activity $38 \%$ after incubation at $60{ }^{\circ} \mathrm{C}$ for $60 \mathrm{~min}$; optimal enzyme activity $23 \mathrm{U} / \mathrm{mg}$ ) [32]. The optimal enzyme activities of mutants D102C-A300C and G103C-T113C were $1567.6 \mathrm{U} / \mathrm{mg}$ and $754.7 \mathrm{U} / \mathrm{mg}$ (determined at OD520), or $1441.4 \mathrm{U} / \mathrm{mg}$ and

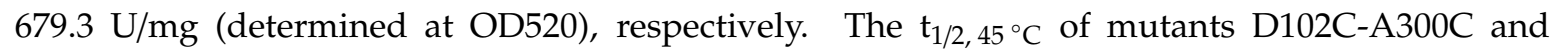
G103C-T113C were $4.15 \mathrm{~h}$ and $3.06 \mathrm{~h}$, respectively, which were 2.18- and 1.61-times higher than

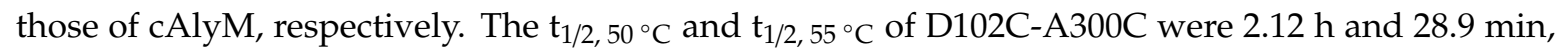
which were 2.02- and 1.9-times higher than those of cAlyM, respectively (data not shown). In addition, the enzyme specific activity of D102C-A300C was 1.13-times higher than that of cAlyM. The catalytic efficiency of D102C-A300C also remarkably improved, with the $k_{\text {cat }} / K_{m}$ value $(3079.2 \mathrm{~mL} / \mathrm{mg} / \mathrm{s})$ being 
$149.4 \%$ higher than that of cAlyM $(2060.7 \mathrm{~mL} / \mathrm{mg} / \mathrm{s})$, which was higher than that reported by previous studies, such as alginate lyase OalC17 (118.78 mL/mg/s) from Cellulophaga sp. SY116 [33] and alginate lyase OalS6 (61.7 mL/mg/s) from Shewanella sp. Kz7 [34].

Previous studies have shown that disulfide bonds, H-bonds, salt bonds, and hydrophobic interactions can enhance protein thermal stability [28,35-37]. The introduction of disulfide bonds in protein structure is the main reason for improving enzymes' thermal stability, which can reduce the entropy of the unfolded protein and stabilize the protein conformation. In previous studies, various enzymes' thermal stability were improved by introducing disulfide bond, such as phytases [20], alkaline $\alpha$-amylase [21], alginate lyase [26], and 1,4- $\beta$-endoglucanase [38]. The newly-formed disulfide bonds D102C-A300C and G103C-T113C that increased the thermal stability of alginate lyase were both located at the protein surface and far from enzyme catalytic center. The formation of new H-bonds increases the thermal stability of cellobiohydrolase Cel7A from Hypocrea jecorina [39], alkaline pectate lyase from Bacillus subtilis 168 [14], and alginate lyase from the Flavobacterium sp. UMI-01 [40]. According to the 3D modeling structure, the H-bonds locus in D102C-A300C changed and hydrophobic interactions in G103C-T113C increased, it might be another reason for the increased thermal stability of the two mutants, in addition to the formation of the disulfide bond. The thermal stability of V59C-Y86C reduced, which is concurrent with a report stating that the disulfide bonds near the $\mathrm{N}$-terminal protein have a negative influence on enzyme thermal stability [26].

cAlyM showed high activity at $45-55{ }^{\circ} \mathrm{C}$, but the activity reduced by more than $50 \%$ after incubation at $45^{\circ} \mathrm{C}$ for $2 \mathrm{~h}$. The thermal stability of cAlyM cannot meet the industrial demand for the preparation of alginate oligosaccharides. In this study, the alginate lyase D102C-A300C was obtained, which exhibited high thermal stability and enzyme activity by the introduction of a disulfide bond. The optimal temperature and $\mathrm{pH}$ of D102C-A300C were $55^{\circ} \mathrm{C}$ and 8.0, respectively. The $K_{m}$ and $k_{\text {cat }}$ values

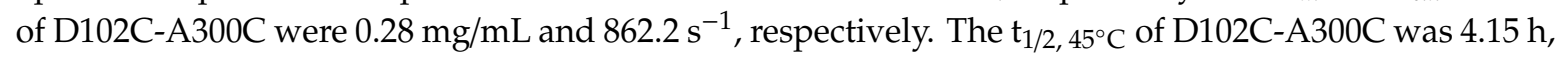
which was 2.18-times higher than that of cAlyM. The newly formed disulfide and hydrogen bonds may contribute to the increase in enzyme thermal stability. When compared with cAlyM, the introduction of the disulfide bond did not change the secondary structure of D102C-A300C. This rational design method, combined with the prediction of disulfide bonds and screening through the analysis of catalytic sites, secondary structure, spatial configuration, and MD simulation, is expected to be widely applied to enhance the thermal stability of other industrial enzymes. The mutant D102C-A300C showed high potential for the development of functional alginate oligosaccharides in food and medicine industries.

\section{Materials and Methods}

\subsection{Strains, Media, and Chemicals}

The recombinant plasmid harboring the alginate lyase gene, named DH5 $\alpha$-HTa-cAlyM, was transformed in E. coli DH5 $\alpha$ and preserved in our lab. The expression system was E. coli BL21 (DE3) cell and pProEX HTa plasmid, which were preserved in our lab. Luria-Bertani (LB) medium comprised of $10 \mathrm{~g} / \mathrm{L} \mathrm{NaCl}, 10 \mathrm{~g} / \mathrm{L}$ tryptone and $5 \mathrm{~g} / \mathrm{L}$ yeast extract $(100 \mu \mathrm{g} / \mathrm{mL}$ ampicillin was added before use). High-fidelity DNA polymerase was purchased from Vazyme Biotech Co., Ltd. (Nanjing, China). The plasmid extraction kit was purchased from Omega Bio-tek, Inc. (Norcross, GA, USA). DpnI, a restriction enzyme, was purchased from Thermo Fisher Scientific (Waltham, MA, USA).

\subsection{Computational Analysis of Enzymes}

Clustal Omega (https://www.ebi.ac.uk/Tools/msa/clustalo/) was used to align the amino acid sequence of cAlyM with other characterized PL7 alginate lyases. Homology modeling of protein structures was performed while using the Phyre2 program (http://www.sbg.bio.ic.ac.uk/phyre2/html/ page.cgi?id=index), and reliability analysis of the model was evaluated by the Ramachandran plot and Profile-3D. Disulfide bonds were predicted by the Predict Disulfide Bridges module of Discovery Studio 2018 (DS2018) (Accelrys, Inc., San Diego, CA, USA). Conjugate gradient algorithm and Standard 
Dynamics Cascade module of DS 2018 were performed to optimize the structure energy and for MD simulation of enzymes, respectively. MD simulation was composed of five stages, viz., two energy minimizations, heating, equilibration, and production stages. In the first energy minimization stage, maximum steps, and root mean square (RMS) gradient parameters were set as 10,000 and 0.2 for the steepest descent. The maximum steps and RMS gradient parameters were set as 10,000 and 0.0001 for conjugate gradient in the second energy minimization stage. For the heating stage, the temperature was increased from 50 to $300 \mathrm{~K}$ during 2000 steps with a time step of $0.002 \mathrm{ps}$. The enzyme model was then equilibrated at $300 \mathrm{~K}$ for $20 \mathrm{ps}$, and data were sampled at $300 \mathrm{~K}$ for 200 ps under constant pressure and temperature dynamics. RMSD and RMSF analyses were performed while using the trajectory analysis module of DS2018. The three-dimensional (3D) molecular structures were visualized while using the PyMOL 2.1.1 software (Delano Scientific, San Carlos, CA, USA).

\subsection{Construction, Expression, and Purification of cAlyM and Its Mutants}

The center of the mutation site and 10-15 bases on both sides were selected as the primer sequence. The primers were designed while using DNAMAN 6.0 (Lynnon Biosoft, San Ramon, CA, USA) (Table 4). DH5 $\alpha$-HTa-cAlyM, extracted while using the plasmid extraction kit, was used as the template to amplify the mutation plasmids. The conditions of PCR were, as follows: $2 \mathrm{~min}$ at $94{ }^{\circ} \mathrm{C}$, followed by 30 cycles of $10 \mathrm{~s}$ at $94{ }^{\circ} \mathrm{C}, 15 \mathrm{~s}$ at $60-68^{\circ} \mathrm{C}$, and $3 \mathrm{~min}$ at $72{ }^{\circ} \mathrm{C}$, with a final extension step for 5 min at $72{ }^{\circ} \mathrm{C}$. The restriction enzyme DpnI was used to remove the template DNA. The PCR product was purified by the Gel Extraction Kit. Recombinant plasmids were confirmed by DNA sequencing (Ruibiotech, Qingdao, China) and transformed into E. coli BL21 (DE3). E. coli BL21 (DE3) cells were cultivated in LB medium with $100 \mu \mathrm{g} / \mathrm{mL}$ ampicillin at $37{ }^{\circ} \mathrm{C}$ until the optical density at $600 \mathrm{~nm}$ reached 0.6-0.8. Subsequently, $0.5 \mathrm{mM}$ isopropyl $\beta$-D-thiogalactopyranoside (IPTG) was added into the medium for induction and the medium was incubated at $23{ }^{\circ} \mathrm{C}$ for $24 \mathrm{~h}$. The fermentation liquor was centrifuged at $8000 \mathrm{rmp}$ for $20 \mathrm{~min}$; the supernatant is the crude enzyme.

Table 4. Primers used in this study.

\begin{tabular}{cc}
\hline Primer $\mathbf{N a m e}$ & Sequence $\mathbf{( 5}^{\prime} \mathbf{}^{\prime} \mathbf{}^{\mathbf{)}}$ \\
\hline V59C-F & GGTACCTGAGCTGTCCTACCGACAAC \\
V59C-R & GTTGTCGGTAGGACAGCTCAGGTACC \\
Y86C-F & CAGATGGCACCTGCTTCTATACTGCTG \\
Y86C-R & CAGCAGTATAGAAGCAGGTGCCATCTG \\
D102C-F & GCTGCCCGATCTGTGGCTATAAAAC \\
D102C-R & GTTTTATAGCCACAGATCGGGCAGC \\
A300C-F & CACCGGCAATTGCAGTGACTATGTC \\
A300C-R & GACATAGTCACTGCAATTGCCGGTG \\
G103C-F & GCCCGATCGATTGCTATAAAACATCG \\
G103C-R & CGATGTTTTATAGCAATCGATCGGGC \\
T113C-F & CACGTCCTATTGCCGCACCGAGCTG \\
T113C-R & CAGCTCGGTGCGGCAATAGGACGTG \\
R122C-F & CGCGAGATGCTATGTCGTGGCGACACC \\
R122C-R & GGTGTCGCCACGACATAGCATCTCGCG \\
N136C-F & GGGTCAATGGATGCAACTGGGTATTCG \\
N136C-R & CGAATACCCAGTTGCATCCATTGACCC \\
S173C-F & CTACCGGAGATTGCGGCCAGGTTGGAC \\
S173C-R & GTCCAACCTGGCCGCAATCTCCGGTAG \\
S229C-F & GGCAGCCGTTCCTGCAGCGCCTCGGAC \\
S229C-R & GTCCGAGGCGCTGCAGGAACGGCTGC \\
V207C-F & GCAAAGGTTCTTGCTATATCGCCCATG \\
V207C-R & CATGGGCGATATAGCAAGAACCTTTGC \\
I224C-F & GGTACGACATGTGTGGCAGCCGTTCC \\
I224C-R & GGAACGGCTGCCACACATGTCGTACC \\
\hline
\end{tabular}


The enzyme with the His6 tag were purified while using the Ni-NTA agarose column (Cube Biotech, Germany), which was pre-equilibrated in $50 \mathrm{mM}$ phosphate buffer containing $100 \mathrm{mM} \mathrm{NaCl}$, pH 7.0 (buffer A). The enzymes were fully absorbed by the Ni-NTA agarose column. The His-tagged target protein was then eluted with buffer A containing 10-400 mM imidazole. The purified enzymes were detected by $12 \%$ sodium dodecyl sulfate-polyacrylamide gel electrophoresis (SDS-PAGE) and then used for further studies after dialysis and ultrafiltration concentration.

\subsection{Determination of Disulfide Bonds Formation}

The formation of disulfide bonds was detected by detecting free amino acids in enzymes. DTNB can quantitatively determine the amount of free sulfhydryl groups in proteins [41]. Two protein samples $(1 \mathrm{~mL})$ were added $1 \mathrm{~mL}$ Tris-Gly buffer $(\mathrm{pH} 8.0)$, one of which was treated with $8 \mathrm{M}$ carbamide and then incubated at $37^{\circ} \mathrm{C}$ for two hours. The treated protein samples were added $50 \mu \mathrm{L} 4 \mathrm{mg} / \mathrm{mL}$ DTNB and the absorbance at $412 \mathrm{~nm}$ was measured to calculate the content of sulfhydryl.

\subsection{Enzyme Activity Assays}

The enzyme activity was determined by the 3,5-dinitrosalicylic acid (DNS) method while using glucose as the standard [42]. The enzymatic reaction was performed in $50 \mathrm{mM}$ sodium phosphate buffer ( $\mathrm{pH} 7.0)$ containing $0.5 \%(\mathrm{w} / \mathrm{v})$ alginate for $10 \mathrm{~min}$. at the optimal temperature. One unit of enzyme (U) was defined as the amount of enzyme causing the release of $1 \mu \mathrm{mol}$ of reducing sugar from alginate per minute. The protein concentration was determined by the Bradford method while using bovine serum albumin as the standard [43].

\subsection{Properties of cAlyM and Its Mutant}

The kinetic parameters of cAlyM were evaluated by determining the enzyme activity while using alginate at different concentrations $(0.05-2.0 \mathrm{mg} / \mathrm{mL})$. The $K_{m}$ and $V_{\max }$ values were calculated by the Lineweaver-Burk method. The optimum temperature for alginate lyase activity was determined in $50 \mathrm{mM}$ sodium phosphate buffer, $\mathrm{pH} 7.0$, at various temperatures ranging from $40^{\circ} \mathrm{C}$ to $60^{\circ} \mathrm{C}$. The optimum $\mathrm{pH}$ for alginate lyase activity was determined at optimum temperature in various buffers (50 mM), including citrate buffer ( $\mathrm{pH} 5.0-6.0)$, phosphate buffer ( $\mathrm{pH}$ 6.0-8.0), and glycine-NaOH buffer ( $\mathrm{pH}$ 9.0). The enzymes were incubated at various temperatures $\left(45-55^{\circ} \mathrm{C}\right)$ for different time periods to determine the thermal stability. The melting temperature $(\mathrm{Tm})$ of the enzyme was determined while using MicroCal PEAQ-DSC Automated (Malvern Panalytical Ltd., Malvern, UK) at an enzyme concentration of $1 \mathrm{mg} / \mathrm{mL}$ in $20 \mathrm{mM}$ phosphate buffer (pH 7.4). The temperature was increased from $25^{\circ} \mathrm{C}$ to $90^{\circ} \mathrm{C}$ at a scan rate of $1{ }^{\circ} \mathrm{C} / \mathrm{min}$.

\subsection{Circular Dichroism (CD) Analysis}

The CD spectra of cAlyM and its mutants were analyzed while using a MOS-450 circular dichroism spectrometer (Bio-logic, France), as described previously [44,45]. The Dichroweb online software was used to estimate the percentages of secondary structures ( $\alpha$-helix, $\beta$-sheet, $\beta$-turns, and loops) [46].

Supplementary Materials: The following are available online at http://www.mdpi.com/1660-3397/17/6/378/s1, Table S1: The results of predication of disulfide bond; Figure S1: The Ramachandran plot (A) and Profile-3D (B) of cAlyM 3D structure; Figure S2: Comparison of surface charge around the mutant sites of cAlyM and its mutants. A: V59C-Y86C; B: D102C-A300C; C: G103C-T113C; D: R122C-N136C; E: S173C-S229C; F: V207C-I224C.

Author Contributions: Conceptualization, M.Y. and H.-J.M.; methodology, M.Y. and Z.-M.L.; experimental work, M.Y., S.-X.Y., and N.-N.L.; analysis of the results, M.Y., L.L. and H.-J.M.; writing-original draft preparation, M.Y.; writing-review and editing, M.Y. and H.-J.M.

Funding: This work was supported by Shandong Province Key Research and Development Project (2017YYSP003), Natural Science Foundation of Shandong Province (ZR2017MD006).

Conflicts of Interest: There are no conflicts to declare. 


\section{References}

1. Chen, X.L.; Sheng, D.; Fei, X.; Fang, D.; Li, P.Y.; Zhang, X.Y.; Zhou, B.C.; Zhang, Y.Z.; Xie, B.B. Characterization of a new cold-adapted and salt-activated polysaccharide lyase family 7 alginate lyase from pseudoalteromonas sp. SM0524. Front. Microbiol. 2016, 7, e30105. [CrossRef] [PubMed]

2. Preiss, J.; Ashwell, G. Alginic acid metabolism in bacteria. I. Enzymatic formation of unsaturated oligosac-charides and 4-deoxy-1-erythro-5-hexoseulose uronic acid. J. Biol. Chem. 1962, 237, 309-316. [PubMed]

3. Chen, J.; Hu, Y.; Zhang, L.; Wang, Y.; Wang, S.; Zhang, Y.; Guo, H.; Ji, D.; Wang, Y. Alginate oligosaccharide DP5 exhibits antitumor effects in osteosarcoma patients following surgery. Front. Pharmacol. 2017, 8, 623. [CrossRef] [PubMed]

4. Wargacki, A.J.; Leonard, E.; Win, M.N.; Regitsky, D.D.; Santos, C.N.S.; Kim, P.B.; Cooper, S.R.; Raisner, R.M.; Herman, A.; Sivitz, A.B.; et al. An engineered microbial platform for direct biofuel production from brown macroalgae. Science 2012, 335, 308-313. [CrossRef] [PubMed]

5. Zhou, R.; Shi, X.; Gao, Y.; Cai, N.; Jiang, Z.; Xu, X. Anti-inflammatory activity of guluronate oligosaccharides obtained by oxidative degradation from alginate in lipopolysaccharide-activated murine macrophage RAW 264.7 cells. J. Agric. Food Chem. 2015, 63, 160-168. [CrossRef]

6. Miyake, O.; Moriwaki, S.; Murata, K.; Yamasaki, M.; Mikami, B.; Hashimoto, W. Structure and function of a hypothetical Pseudomonas aeruginosa protein PA1167 classified into family PL7: A novel alginate lyase with a beta-sandwich fold. J. Biol. Chem. 2004, 279, 31863-31872.

7. Rahman, M.M.; Wang, L.; Inoue, A.; Ojima, T. cDNA cloning and bacterial expression of a PL-14 alginate lyase from a herbivorous marine snail littorina brevicula. Carbohydr. Res. 2012, 360, 69-77. [CrossRef]

8. Zhu, B.; Tan, H.; Qin, Y.; Xu, Q.; Du, Y.; Yin, H. Characterization of a new endo-type alginate lyase from vibrio sp. W13. Int. J. Biol. Macromol. 2015, 75, 330-337. [CrossRef]

9. Liu, Y.; Huang, L.; Jia, L.; Gui, S.; Fu, Y.; Zheng, D.; Guo, W.; Lu, F.P. Improvement of the acid stability of Bacillus licheniformis alpha amylase by site-directed mutagenesis. Process Biochem. 2017, 58, 174-180. [CrossRef]

10. Couturier, M.; Féliu, J.; Bozonnet, S.; Roussel, A.; Berrin, J.G. Molecular engineering of fungal GH5 and GH26 beta-(1,4)-mannanases toward improvement of enzyme activity. PLoS ONE 2013, 8, e79800. [CrossRef]

11. Rha, E.; Kim, S.; Choi, S.L.; Hong, S.P.; Sung, M.H.; Song, J.J.; Lee, S.G. Simultaneous improvement of catalytic activity and thermal stability of tyrosine phenol-lyase by directed evolution. FEBS J. 2010, 276, 6187-6194. [CrossRef]

12. Wu, X.; Tian, Z.; Jiang, X.; Zhang, Q.; Wang, L. Enhancement in catalytic activity of Aspergillus niger XynB by selective site-directed mutagenesis of active site amino acids. Appl. Microbiol. Biotechnol. 2017, 102, 1-12. [CrossRef] [PubMed]

13. Jang, C.H.; Piao, Y.L.; Huang, X.; Yoon, E.J.; Park, S.H.; Lee, K.; Zhan, C.G.; Cho, H. Modeling and re-engineering of Azotobacter vinelandii alginate lyase to enhance its catalytic efficiency for accelerating biofilm degradation. PLoS ONE 2016, 11, e0156197. [CrossRef] [PubMed]

14. Wang, X.; Lu, Z.; Xu, T.; Selvaraj, J.N.; Yi, L.; Zhang, G. Improving the specific activity and thermo-stability of alkaline pectate lyase from Bacillus subtilis 168 for bioscouring. Biochem. Eng. J. 2018, 129, 74-83. [CrossRef]

15. Wu, T.H.; Chen, C.C.; Cheng, Y.S.; Ko, T.P.; Lin, C.Y.; Lai, H.L.; Huang, T.Y.; Liu, J.R.; Guo, R.T. Improving specific activity and thermostability of Escherichia coli phytase by structure-based rational design. J. Biotechnol. 2014, 175, 1-6. [CrossRef] [PubMed]

16. Zhuang, J.; Zhang, K.; Liu, X.; Liu, W.; Lyu, Q.; Ji, A. Characterization of a novel polyM-preferred alginate lyase from marine Vibrio splendidus OU02. Mar. Drugs 2018, 16, 295. [CrossRef] [PubMed]

17. Mansfeld, J.; Vriend, G.; Dijkstra, B.W.; Veltman, O.R.; Van den Burg, B.; Venema, G.; Ulbrich-Hofmann, R.; Eijsink, V.G. Extreme stabilization of a thermolysin-like protease by an engineered disulfide bond. J. Biol. Chem. 1997, 272, 11152-11156. [CrossRef]

18. Liu, T.; Wang, Y.; Luo, X.; Li, J.; Reed, S.A.; Xiao, H.; Young, T.S.; Schultz, P.G. Enhancing protein stability with extended disulfide bonds. Proc. Nati. Acad. Sci. USA 2016, 113, 5910. [CrossRef]

19. Le, Q.A.T.; Joo, J.C.; Yoo, Y.J.; Yong, H.K. Development of thermostable Candida antarctica lipase B through novel in silico design of disulfide bridge. Biotechnol. Bioeng. 2012, 109, 867-876. [CrossRef] 
20. Tan, H.; Miao, R.; Liu, T.; Cao, X.; Wu, X.; Xie, L.; Huang, Z.; Peng, W.; Gan, B. Enhancing thermal resistance of a novel acidobacteria-derived phytase by engineering of disulfide bridges. J. Microbiol. Biotechnol. 2016, 26, 1717-1722. [CrossRef]

21. Liu, L.; Deng, Z.; Yang, H.; Li, J.; Shin, H.D.; Chen, R.R.; Chen, J. In silico rational design and systems engineering of disulfide bridges in the catalytic domain of an alkaline $\alpha$-amylase from Alkalimonas amylolytica to improve thermostability. Appl. Environ. Microbiol. 2014, 80, 798-807. [CrossRef] [PubMed]

22. Yang, M.; Li, N.N.; Yang, S.X.; Yu, Y.; Han, Z.L.; Li, L.; Mou, H.J. Study on expression and action mode of recombinant alginate lyases based on conserved domains reconstruction. Appl. Microbiol. Biotechnol. 2018, 103, 807-817. [CrossRef] [PubMed]

23. Ellman, G.L. Tissue sulfhydryl groups. Arch. Biochem. Biophys. 1959, 82, 70-77. [CrossRef]

24. Miller, G. Use of dinitrosalicylic acid reagent for determination of reducing sugar. Anal. Chem. 1959, 31, 426-428. [CrossRef]

25. Bradford, M.M. A rapid and sensitive method for the quantitation of microgram quantities of protein utilizing the principle of protein-dye binding. Anal. Biochem. 1976, 72, 248-254. [CrossRef]

26. Niu, C.; Zhu, L.; Xu, X.; Li, Q. Rational design of disulfide bonds increases thermostability of a mesophilic 1,3-1,4- $\beta$-glucanase from Bacillus terquilensis. PLoS ONE 2016, 11, e0154036. [CrossRef]

27. Yang, M.; Yu, Y.; Yang, S.X.; Shi, X.H.; Mou, H.J.; Li, L. Expression and characterization of a new polyG-specific alginate lyase from marine bacterium Microbulbifer sp. Q7. Front. Microbiol. 2018, 9, 2894. [CrossRef]

28. Whitmore, L.; Wallace, B.A. Protein secondary structure analyses from circular dichroism spectroscopy: Methods and reference databases. Biopolymers 2008, 89, 392-400. [CrossRef]

29. Inoue, A.; Mashino, C.; Uji, T.; Saga, N.; Mikami, K.; Ojima, T. Characterization of an eukaryotic PL7 alginate lyase in the marine red alga Pyropia yezoensis. Curr. Biotechnol. 2015, 4, 240-248. [CrossRef]

30. Yagi, H.; Fujise, A.; Itabashi, N.; Ohshiro, T. Purification and characterization of a novel alginate lyase from the marine bacterium Cobetia sp. NAP1 isolated from brown algae. Biosci. Biotechno. Biochem. 2016, 80, 2338-2346. [CrossRef]

31. Li, H.; Wang, S.; Zhang, Y.; Chen, L. High-level expression of a thermally stable alginate lyase using pichia pastoris, characterization and application in producing brown alginate oligosaccharide. Mar. Drugs 2018, 16, 158. [CrossRef] [PubMed]

32. Pei, X.; Chang, Y.; Shen, J. Cloning, expression and characterization of an endo-acting bifunctional alginate lyase of marine bacterium Wenyingzhuangia fucanilytica. Protein Express. Purify. 2019, 154, 44-51. [CrossRef] [PubMed]

33. Li, S.; Wang, L.; Chen, X.; Zhao, W.; Sun, M.; Han, Y. Cloning, expression, and biochemical characterization of two new oligoalginate lyases with synergistic degradation capability. Mar. Biotechnol. 2018, 20, 75-86. [CrossRef]

34. Wang, L.; Li, S.; Yu, W.; Gong, Q. Cloning, overexpression and characterization of a new oligoalginate lyase from a marine bacterium Shewanella sp. Biotechnol. Lett. 2015, 37, 665-671. [CrossRef] [PubMed]

35. Kumar, S.; Tsai, C.J.; Ma, B.; Nussinov, R. Contribution of salt bridges toward protein thermostability. J. Biomol. Struct. Dyn. 2000, 17, 79-85. [CrossRef] [PubMed]

36. Mamonova, T.B.; Glyakina, A.V.; Galzitskaya, O.V.; Kurnikova, M.G. Stability and rigidity/flexibility-two sides of the same coin? Biochim. Biophys. Acta 2013, 1834, 854-866. [CrossRef]

37. Li, P.Y.; Chen, X.L.; Ji, P.; Li, C.Y.; Wang, P.; Zhang, Y.; Xie, B.B.; Qin, Q.L.; Su, H.N.; Zhou, B.C.; et al. Interdomain hydrophobic interactions modulate the thermostability of microbial esterases from the hormone-sensitive lipase family. J. Biol. Chem. 2015, 290, 11188-11198. [CrossRef]

38. Badieyan, S.; Bevan, D.R.; Zhang, C. Study and design of stability in GH5 cellulases. Biotechnol. Bioeng. 2012, 109, 31-44. [CrossRef]

39. Goedegebuur, F.; Dankmeyer, L.; Gualfetti, P.; Karkehabadi, S.; Hansson, H.; Jana, S.; Huynh, V.; Kelemen, B.R.; Kruithof, P.; Larenas, E.A.; et al. Improving the thermal stability of cellobiohydrolase Cel7A from Hypocrea jecorina by directed evolution. J. Biol. Chem. 2017, 292, 17418-17430. [CrossRef]

40. Qin, H.M.; Miyakawa, T.; Inoue, A.; Nishiyama, R.; Nakamura, A.; Asano, A.; Ojima, T.; Tanokura, M. Structural basis for controlling the enzymatic properties of polymannuronate preferred alginate lyase FlAlyA from the PL-7 family. Chem. Commun. 2018, 54, 555-558. [CrossRef] 
41. Inoue, A.; Anraku, M.; Nakagawa, S.; Ojima, T. Discovery of a novel alginate lyase from Nitratiruptor sp. SB155-2 thriving at deep-sea hydrothermal vents and identification of the residues responsible for its heat stability. J. Biol. Chem. 2016, 291, 5551-15563. [CrossRef] [PubMed]

42. Yamasaki, M.; Ogura, K.; Hashimoto, W. A structural basis for depolymerization of alginate by polysaccharide lyase family-7. J. Mol. Biol. 2005, 352, 11-21. [CrossRef] [PubMed]

43. Petersen, M.T.N.; Jonson, P.H.; Petersen, S.B. Amino acid neighbours and detailed conformational analysis of cysteines in proteins. Protein Eng. 1999, 12, 535-548. [CrossRef] [PubMed]

44. Ning, X.; Zhang, Y.; Yuan, T. Enhanced thermostability of glucose oxidase through computer-aided molecular design. Int. J. Mol. Sci. 2018, 19, 425. [CrossRef] [PubMed]

45. Radestock, S.; Gohlke, H. Protein rigidity and thermophilic adaptation. Proteins 2015, 79, $1089-1108$. [CrossRef] [PubMed]

46. Yu, H.; Huang, H. Engineering proteins for thermostability through rigidifying flexible sites. Biotechnol. Adv. 2014, 32, 308-315. [CrossRef]

(C) 2019 by the authors. Licensee MDPI, Basel, Switzerland. This article is an open access article distributed under the terms and conditions of the Creative Commons Attribution (CC BY) license (http://creativecommons.org/licenses/by/4.0/). 